\title{
Minimum Wages, Employment and Monopsonistic Competition*
}

\author{
V. Bhaskar \\ University of Essex
}

Ted To

Bureau of Labor Statistics

August 2003

\begin{abstract}
We set out a model of monopsonistic competition, where each employer competes equally with every other employer. The employment effects of minimum wages depend on the degree of distortion in the labor market. If fixed costs per firm are high then the labor market is relatively non-competitive and minimum wages increase employment. Conversely, low fixed costs make for a more competitive labor market where minimum wages reduce employment. This contrasts with the results of a Salop style model with localized employer competition where a minimum wage unambiguously raises employment. We also find that the welfare effect of a small minimum wage is unambiguously positive.
\end{abstract}

Keywords: monopsonistic competition, labor theory, minimum wages, monopsony JEL classification codes: J23, J42, L13

*We thank Greg Kurtzon, Randy Verbrugge and seminar participants at the 2003 Western Economic Association meeting in Denver for helpful comments and suggestions. V. Bhaskar is grateful to the Economic and Social Research Council, UK for its support under research grant L138251029. The views expressed are not to be attributed to the Bureau of Labor Statistics or to the Department of Labor. 


\title{
Minimum Wages, Employment and Monopsonistic Competition
}

\begin{abstract}
We set out a model of monopsonistic competition, where each employer competes equally with every other employer. The employment effects of minimum wages depend on the degree of distortion in the labor market. If fixed costs per firm are high then the labor market is relatively non-competitive and minimum wages increase employment. Conversely, low fixed costs make for a more competitive labor market where minimum wages reduce employment. This contrasts with the results of a Salop style model with localized employer competition where a minimum wage unambiguously raises employment. We also find that the welfare effect of a small minimum wage is unambiguously positive.
\end{abstract}

Keywords: monopsonistic competition, labor theory, minimum wages, monopsony JEL classification codes: J23, J42, L13 


\section{Introduction}

The view that labor markets are imperfectly competitive, with employers possessing some market power, has gained prominence in recent years. Empirical studies have come up with many findings, such as the positive employment effects of minimum wages (Card and Krueger, 1995), that are inconsistent with models of perfect competition. Two alternative approaches to modelling imperfect competition are search models (Burdett and Mortensen, 1998) and models of monopsonistic competition (Bhaskar and To, 1999). ${ }^{1}$

In this paper, we provide a simple model of monopsonistic competition in the labor market. Workers have heterogeneous preferences over employer characteristics, and each employer competes equally with every other employer in seeking to attract workers. This may be contrasted with the circle model of monopsonistic competition in Bhaskar and To (1999), where each employer effectively competes only with her two immediate neighbors. Our model may be viewed as a Dixit-Stiglitz type model, since each firm competes with every other firm, and when the number of firms is large, yields establishment labor supply curves with approximately constant wage elasticity. However, we emphasize that it is not a representative worker model-rather, it is based on heterogenous workers, each of whom chooses to work for at most one employer. Our model is an adaptation of Sattinger's (1984) model of consumer choice to the labor market. This adaptation results in some technical difficulties, since a realistic model of labor markets must allow for the possibility that some workers may be unemployed.

We use this model to study the effects of a minimum wage upon employment in a free entry equilibrium. As in other models of monopsonistic competition, a minimum wage has two conflicting effects. First, it has the standard monopsony effect whereby a moder-

\footnotetext{
${ }^{1}$ Bhaskar et al. (2002) provide a discussion of the empirical evidence, and argue that models of oligopsony/monopsonistic competition provide a parsimonious explanation for much of this evidence. Manning (2002) is a textbook on labor economics with an approach centered on models with employer market power.
} 
ately chosen minimum wage reduces the marginal cost of labor, increasing labor supplied to individual firms. Second, it has a first order negative effect on profits, causing firms to exit, thus reducing employment. We find that the net effect of a small minimum wage can be either positive or negative, depending upon parameter values. If fixed costs are high, so that the equilibrium number of firms is small, and the labor market is relatively non-competitive, then a small minimum wage increases employment. On the other hand, if fixed costs are low, so that the labor market is relatively competitive, a minimum wage reduces employment. In other words, the employment effect of a minimum wage is related to the extent to which the labor market is distorted. These results may be contrasted with those obtained in the context of the circle model of the labor market used by Bhaskar and To (1999). Walsh (2001) shows that in the circle model, the effect of a small minimum wage upon employment is unambiguously positive. ${ }^{2}$

Interestingly, under some parameter configurations with the current model, minimum wages can increase employment even when the labor market has many employers or when the establishment level labor supply elasticity is high. This is of importance because one common argument is that even if there are labor market distortions, these distortions become insignificant in industries like fast food, where many employers compete for workers. Our results show that even when a labor market appears to be competitive, minimum wages can increase employment.

Finally, extensive numerical computations suggest that welfare unambiguously increases when a minimum wage is imposed just above the equilibrium wage rate. That is, the welfare gain due to increased wages outweighs the welfare loss resulting from the reduction of job choices due to employer exit and from (potential) disemployment.

\footnotetext{
${ }^{2}$ Walsh corrects and clarifies the formulation in Bhaskar and To. Although Walsh shows that it is possible to modify the circle model to produce negative employment effects, these modifications require somewhat unreasonable parameter restrictions. Further, these restrictions do not have an intuitive interpretation in terms of the extent of labor market distortions.
} 


\section{The Model}

To ensure that labor supply is imperfectly elastic, we assume that different jobs have different non-wage characteristics. These include the job specification, hours of work, distance of the firm from the worker's home, the social environment in the workplace, etc. The importance of non-wage characteristics has been recognized in the theory of compensating differentials, which is a theory of vertical differentiation. Some jobs are good while other jobs are bad, and wage differentials compensate workers for these differences in characteristics. We assume that jobs are horizontally differentiated so that workers have heterogenous preferences over these characteristics. McCue and Reed (1996) provide survey evidence of horizontal heterogeneity in worker preferences. Heterogeneous preferences over non-wage characteristics ensures that each employer has market power in wage setting, even if it competes with many other employers.

Our modelling of the labor market is inspired by Sattinger's (1984) model of the product market. The key difference is that we allow for unemployment ("home production"). Let us suppose that the individual worker has the following utility function:

$$
U=W^{1-\gamma} L^{\gamma}
$$

where $W$ is the worker's job-adjusted income (defined below) and $L$ is time spent at leisure activities. Let firms be indexed by $j \in\{1,2, \ldots, n\}$. Each firm offers a "job" that has characteristics that differ from its rivals and workers have heterogeneous preferences over these characteristics. We shall also assume that the alternative to outside employment is home production which we denote as job 0.

The worker's preferences over this set of $n+1$ alternatives are parameterized by the $n+1$ vector $\mathbf{r}$ whose generic component $r_{j}$ is a measure of the worker's disutility from activity $j$. In particular, a larger value of $r_{j}$ reduces the value of working for employer $j$, 
at the offered wage $w_{j}$. More specifically, we model this as follows. If a worker works $h_{j}$ hours for wage $w_{j}$ and has disutility $r_{j}$ for working at job $j$ then her disutility-adjusted earnings from job $j$ are $w_{j} h_{j} / r_{j}$ and her total job-disutility-adjusted income from all jobs is $W=\sum_{j=0}^{n} w_{j} h_{j} / r_{j}$. Workers have likes and dislikes over job characteristics and an unpleasant job (i.e., one for which $r_{j}$ is large) reduces the pleasure that a worker gets from her income. We assume that the return to home production, $w_{0}$, is exogenously specified. If $\bar{L}$ is the total amount of leisure time available then she enjoys $L=\bar{L}-\sum_{j=0}^{n} h_{j}$ hours of leisure.

Taking the first order conditions yield:

$$
\frac{\partial U}{\partial h_{j}}=(1-\gamma) \frac{w_{j}}{r_{j}}\left(\frac{L}{W}\right)^{\gamma}-\gamma\left(\frac{W}{L}\right)^{1-\gamma} \leq 0
$$

for $j=0,1, \ldots, n$. For generic values of $\mathbf{r}$, this condition will hold with equality for exactly one employer and with strict inequality for all other employers. This implies that individual workers will work for at most one employer. Let $j=\arg \max _{k}\left\{w_{k} / r_{k}\right\}$ represent the employer for whom the first order condition holds with equality. Solving equation (2), the worker's labor supply to employer $j$ is $h_{j}=(1-\gamma) \bar{L}$ and for all employers $k \neq j$ is $h_{k}=0$. If $j$ happens to be home production, the worker will be unemployed.

Suppose that there is a unit mass of workers and that for each worker, her disutilities, $r_{j}$, are independently and identically distributed with a continuous distribution function $F$ and corresponding probability density function $f$. The conditional probability given $r_{j}$ that the worker prefers employer $j$ to employer $k$ is $1-F\left(r_{j} w_{k} / w_{j}\right)$. Thus the conditional probability given $r_{j}$ that the worker prefers employer $j$ to all other employers and to staying at home is $\prod_{k \neq j}\left[1-F\left(r_{j} w_{k} / w_{j}\right)\right]$. Multiplying individual labor supply by this 
probability and integrating over all $r_{j}$ yields labor supply to firm $j$

$$
L_{j}=(1-\gamma) \bar{L} s_{j}
$$

where $s_{j}$ is firm $j^{\prime}$ s share of total labor supplied (either for work or for home production) and is given by:

$$
s_{j}=\int \prod_{k \neq j}\left[1-F\left(\frac{r_{j} w_{k}}{w_{j}}\right)\right] f\left(r_{j}\right) d r_{j} .
$$

For the case when all firms but $j$ offer wage $w_{-j}$, this becomes:

$$
s_{j}=\int\left[1-F\left(\frac{r_{j} w_{-j}}{w_{j}}\right)\right]^{n-1}\left[1-F\left(\frac{r_{j} w_{0}}{w_{j}}\right)\right] f\left(r_{j}\right) d r_{j} .
$$

Suppose that $F$ is the Pareto distribution so that $F(x)=1-(b / x)^{a}$ and $f(x)=a b^{a} / x^{a+1}$ where $a, b>0$ and $x \geq b$. Consider employer $j$ 's labor supply when all rival employers offer wage $w_{-j}$ and $w_{j}, w_{-j}>w_{0}$. The equation for firm $j$ 's share of labor supplied can be written as:

$s_{j}= \begin{cases}{\left[1-\left(\frac{w_{-j}}{w_{j}}\right)^{a}\right]+\frac{1}{n}\left[\left(\frac{w_{-j}}{w_{j}}\right)^{a}-\left(\frac{w_{0}}{w_{-j}}\right)^{a(n-1)}\left(\frac{w_{0}}{w_{j}}\right)^{a}\right]+\frac{1}{n+1}\left(\frac{w_{0}}{w_{-j}}\right)^{a(n-1)}\left(\frac{w_{0}}{w_{j}}\right)^{a}} & \text { if } w_{j} \geq w_{-j} \\ \frac{1}{n}\left[\left(\frac{w_{j}}{w_{-j}}\right)^{a(n-1)}-\left(\frac{w_{0}}{w_{-j}}\right)^{a(n-1)}\left(\frac{w_{0}}{w_{j}}\right)^{a}\right]+\frac{1}{n+1}\left(\frac{w_{0}}{w_{-j}}\right)^{a(n-1)}\left(\frac{w_{0}}{w_{j}}\right)^{a} & \text { if } w_{j} \leq w_{-j}\end{cases}$

For the case when $w_{j}, w_{-j}<w_{0}, s_{j}$ can be written as:

$$
s_{j}= \begin{cases}\frac{1}{2}\left[\left(\frac{w_{j}}{w_{0}}\right)^{a}-\left(\frac{w_{-j}}{w_{0}}\right)^{a}\left(\frac{w_{-j}}{w_{j}}\right)^{a}\right]+\frac{1}{n+1}\left(\frac{w_{-j}}{w_{0}}\right)^{a}\left(\frac{w_{-j}}{w_{j}}\right)^{a} & \text { if } w_{j} \geq w_{-j} \\ \frac{1}{n+1}\left(\frac{w_{j}}{w_{-j}}\right)^{a(n-1)}\left(\frac{w_{j}}{w_{0}}\right)^{a} & \text { if } w_{j} \leq w_{-j}\end{cases}
$$

These expressions are rather complicated, however, for the case with symmetric wages (i.e., $w_{j}=w_{-j}=w$ ), the establishment level elasticity of labor supply is given by the 
following, relatively simple expression:

$$
\varepsilon=\left\{\begin{array}{ll}
\frac{a\left((n+1)(n-1)+\left(\frac{w_{0}}{w}\right)^{a n}\right)}{(n+1)-\left(\frac{w_{0}}{w}\right)^{a n}} & \text { if } w \geq w_{0} \\
a n & \text { if } w \leq w_{0}
\end{array} .\right.
$$

This is a weakly decreasing, continuous function of $w$ and is bounded by $a(n-1)$ and an. That is, as the market wage rate rises, the elasticity of labor supply falls. This is what should be expected since if the wage is high relative to the return from home production, home production becomes a less attractive substitute. Moreover, $\varepsilon$ is an increasing function of the number of firms, $n$. Differentiating $\varepsilon$ with respect to $n$ we get:

$$
\frac{\partial \varepsilon}{\partial n}=\left\{\begin{array}{ll}
\frac{a\left((n+1)^{2}-(2 n+1)\left(\frac{w_{0}}{w}\right)^{a n}+(n+1)\left(\frac{w_{0}}{w}\right)^{a n} \ln \left(\frac{w_{0}}{w}\right)^{a n}\right)}{\left(n+1-\left(\frac{w_{0}}{w}\right)^{a n}\right)^{2}} & \text { if } w \geq w_{0} \\
a & \text { if } w \leq w_{0}
\end{array} .\right.
$$

Consider the case when $w \geq w_{0}$. Since $-(2 n+1) x+(n+1) x \ln x$ is strictly decreasing for all $x \leq 1$, it follows that the minimum value of numerator is $a n^{2}$. Thus we can conclude that $\partial \varepsilon / \partial n>0$. As should be expected, establishment level labor supply becomes more elastic as the number of employers increases. In particular we have the desirable result that as the number of firms, $n$, grows large, the labor market approaches perfect competition with establishment labor supply curves becoming perfectly (infinitely) elastic.

For a fixed number of firms in a symmetric equilibrium, wages will be set according to the rule,

$$
w(n)=\phi \frac{\varepsilon}{1+\varepsilon}
$$

where $\phi$ is the marginal revenue product of labor. ${ }^{3}$ Thus wages are a strictly increasing

\footnotetext{
${ }^{3}$ The assumption, that the marginal revenue product of labor is constant, is not really necessary. If both capital and labor are required, and there is constant returns to scale and a competitive capital market, Bhaskar and To (1999) show that when the capital labor ratio adjusts optimally, the "net revenue product"
} 
function of the labor supply elasticity. This implies that there is a unique, symmetric equilibrium wage, $w^{*}(n)$, satisfying equations (7) and (9). ${ }^{4}$ Moreover, since labor supply elasticity rises with the number of employers, equilibrium wages do so as well.

Given the equilibrium wage rate, $w^{*}(n)$, the equilibrium share of labor per firm is given by

$$
s^{*}(n)= \begin{cases}\frac{1}{n}\left[1-\left(\frac{w_{0}}{w^{*}(n)}\right)^{a n}\right]+\frac{1}{n+1}\left(\frac{w_{0}}{w^{*}(n)}\right)^{a n} & \text { if } w^{*}(n) \geq w_{0} \\ \frac{1}{n+1}\left(\frac{w^{*}(n)}{w_{0}}\right)^{a} & \text { if } w^{*}(n) \leq w_{0}\end{cases}
$$

As should be expected, if $w^{*}(n)=w_{0}$ then each of the $n+1$ activities garners an equal share of labor supplied-i.e., $s^{*}(n)=1 /(n+1)$.

The equilibrium profits of the firm are given by

$$
\pi^{*}(n)=\left(\phi-w^{*}(n)\right) L^{*}(n)
$$

where $L^{*}(n)=(1-\gamma) \bar{L} s^{*}(n)$. This is decreasing in the number of firms for two reasons. First, labor supply per firm is decreasing in $n$, and second, the wage is also higher with $n$. To see the former, examine equation (13). The numerator is a scalar multiple of the numerator of (8) and by similar argument we can show that $\varepsilon_{n}<0$. Since labor supply falls and wages rise with $n$, profits must fall with $n$. The free entry number of firms is an $n^{*}$ such that $\pi^{*}\left(n^{*}\right)-c=0$ where $c$ is the fixed cost of production.

\section{The effects of a minimum wage}

When a minimum wage is imposed, establishment level employment rises due to the monopsony effect, but total employment may fall because of induced firm exit. Recall is constant.

${ }^{4}$ As noted by Sattinger (1984), there may well exist other, asymmetric equilibria. For tractability, we focus only on the symmetric equilibrium. 
that establishment level employment is given by:

$$
L(n)=(1-\gamma) \bar{L} s_{j}
$$

where $s_{j}$ is as given in equations (6a) and (6b).

Let $E$ denote total employment, $L n$. In order to work out the employment effect of a minimum wage under free entry, we utilize the following decomposition, due to Walsh (2001):

$$
\frac{d E}{d w^{m}}=\frac{L n}{w}\left(\varepsilon-\frac{\varepsilon_{-j}}{\varepsilon_{n}}\right)
$$

where $\varepsilon$ is the elasticity of firm labor supply with respect to the own wage, $\varepsilon_{-j}$ is the elasticity with respect to competitor firm wages, and $\varepsilon_{n}$ is the elasticity with respect to $n$.

The own wage elasticity of labor supply is given by equation (7). From the equation for labor supply, $\varepsilon_{-j}$ and $\varepsilon_{n}$ are as follows:

$$
\begin{gathered}
\varepsilon_{-j}=-a(n-1) \\
\varepsilon_{n}=\left\{\begin{array}{ll}
-\frac{(n+1)^{2}-(2 n+1)\left(\frac{w_{0}}{w}\right)^{a n}+(n+1)\left(\frac{w_{0}}{w}\right)^{a n} \ln \left(\frac{w_{0}}{w}\right)^{a n}}{(n+1)\left\{n+1-\left(\frac{w_{0}}{w}\right)^{a n}\right\}} & \text { if } w \geq w_{0} \\
-\frac{n}{n+1} & \text { if } w \leq w_{0}
\end{array} .\right.
\end{gathered}
$$

It is straightforward to show that there exist parameter values such that the employment effect of a minimum wage is positive. For example, consider parameter values such that $w^{*} \leq w_{0} \cdot{ }^{5}$ In this case, $\varepsilon=$ an and $\varepsilon_{n}=-n /(n+1)$, so that

$$
\frac{d E}{d w^{m}}=\frac{L}{w} a
$$

That is, if the equilibrium wage is sufficiently small relative to the return from home

\footnotetext{
${ }^{5}$ Since the equilibrium wage, $w^{*}$, is bounded above by $\phi$, we may choose $\phi$ so that $w^{*}$ is smaller than $w_{0}$.
} 
production, a minimum wage increases employment.

Unfortunately, general conditions for negative employment effects are not possible because of the non-linearity of the equilibrium system of equations. For this reason, we numerically compute the equilibria for a wide range of parameters to establish that minimum wages can lower employment. We present a selection of these results in Table 1. These results show that fixing other parameter values, the minimum wage effect depends upon the fixed $\operatorname{cost} c$. When fixed costs are relatively low, a minimum wage reduces employment. When the fixed cost is large, minimum wages increase employment. Since fixed costs are the factor which prevent perfect competition from occurring, our results have an intuitive interpretation-minimum wages raise employment when the labor market is distorted, but reduce employment when the market is relatively competitive. Note however that even for labor markets that appear to be highly competitive to a casual observer (e.g., $n>850$ or $\varepsilon>90$ ), a minimum wage can still have a positive employment effect. That is, even if a labor market appears, prima facie, to be competitive, a minimum wage may increase employment under monopsonistic competition.

\subsection{Welfare Effects}

Let us now consider the utility of an individual with disutilities $\mathbf{r}=\left(r_{0}, r_{1}, \ldots r_{n}\right)$. Suppose the equilibrium wage profile is $\mathbf{w}=\left(w_{0}, w_{1}, \ldots w_{n}\right)$. This worker will spend $(1-\gamma) \bar{L}$ hours at activity $j$ where $j=\arg \max w_{j} / r_{j}$ and $\gamma \bar{L}$ hours at leisure activities. Her indirect utility can be written as:

$$
U(\mathbf{w}, \mathbf{r})=K \max \left(\frac{w_{j}}{r_{j}}\right)^{1-\gamma}
$$


Table 1: Employment and welfare effects

\begin{tabular}{|c|c|c|c|c|c|c|c|c|}
\hline$a$ & $w_{0}$ & $c$ & $n$ & $w^{*}$ & l & 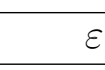 & $\begin{array}{l}\begin{array}{l}\text { employment } \\
\text { effect }\end{array} \\
\text { ent }\end{array}$ & $\begin{array}{l}\text { Welfare } \\
\text { effect }\end{array}$ \\
\hline$\overline{01}$ & 0.90 & 0.00002 & 331.9 & 939 & 00033 & 15.3 & $=0.003379$ & $\overline{0.016}$ \\
\hline 0.01 & 90 & & 68.8 & 914 & & 10.7 & -0.0 & 0.02 \\
\hline 0.01 & 90 & & 63.7 & 896 & & 8.6 & & .028 \\
\hline 0.01 & 90 & 0.00008 & 741.5 & .881 & 00067 & 7.4 & 0.000014 & 0.032 \\
\hline 0.01 & 95 & 000005 & 112.6 & .969 & 00016 & 31.1 & -0.00332 & .0081 \\
\hline 0.01 & 95 & & 86.2 & 956 & & 21.9 & & 011 \\
\hline 01 & 95 & & 775.9 & .947 & & 17.8 & & .0140 \\
\hline 01 & 0.95 & 0 & 531.3 & 0.939 & & 15.3 & & 0.0161 \\
\hline 0.25 & $\overline{90}$ & & $\overline{61.2}$ & $\overline{0.94}$ & & 15.2 & & 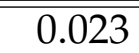 \\
\hline 25 & & & 42.2 & & & 10.6 & & 33 \\
\hline 25 & & & 34.0 & & & 8 & & 040 \\
\hline 25 & 90 & & 29.1 & 0.88 & & 7.3 & & .045 \\
\hline 0.25 & 5 & & 139.5 & 972 & & 34.7 & & 11 \\
\hline 0.25 & & & 2 & & & .8 & & 018 \\
\hline 25 & & & 60 & & & & & .023 \\
\hline 25 & 0.95 & & 50.8 & 927 & & 12.7 & & 0.027 \\
\hline 0.25 & 0.99 & & 0.4 & 0.994 & & 57.5 & & .0024 \\
\hline 0.25 & 99 & & 4.8 & 1 & & 111.2 & & .0033 \\
\hline 0.25 & 99 & & 1.6 & 9 & & 90 & & .0041 \\
\hline 0.25 & 0.99 & 0 & 313.6 & 0.987 & & 78.4 & 008 & 0.0047 \\
\hline$\overline{10}$ & 0 & & & $\overline{0}$ & & $\overline{14.8}$ & & $\overline{04}$ \\
\hline 00 & & & 10.3 & & & 10.2 & & .062 \\
\hline 00 & & & 8. & 0.8 & & 8. & 124 & 0.075 \\
\hline 1.00 & 90 & & 6.8 & 0.87 & 62 & 6.8 & 148 & 0.084 \\
\hline 1.00 & 0.95 & & 31.1 & 968 & 58 & 30.6 & -0.303 & 0.023 \\
\hline 1.00 & 0.95 & & & & & 14 & 64 & .032 \\
\hline 1.00 & & & & & & & & .039 \\
\hline 1.00 & 0.95 & & 4.7 & 36 & & 14.7 & .068 & 0.045 \\
\hline 1.00 & 0.99 & & 7.6 & 94 & & 157.1 & 321 & 0.0047 \\
\hline 1.00 & & & 110.9 & & & 110.8 & 97 & 0.0067 \\
\hline 1.00 & & & & & & & 11 & 0.0081 \\
\hline 1.00 & 0.99 & 0.00008 & 78.0 & 0.987 & 0.0063 & 78.0 & 0.013 & 0.009 \\
\hline
\end{tabular}

Notes: The employment and welfare effects are elasticities with respect to the minimum wage. For these computations, we fix various scale parameters as follows: $\gamma=0.5, b=1, \phi=1$ and $\bar{L}=1$. These numeric results were computed using a FORTRAN program employing the non-linear equation solver from the Argonne National Laboratory's collection of optimization subroutines, MINPACK-1. 
where $K=(1-\gamma)^{1-\gamma} \gamma^{\gamma} \bar{L}$. For symmetric wage profiles where $w_{j}=w$ for $j=1,2, \ldots n$, indirect utility can be rewritten as:

$$
U\left(x_{e}, x_{u}\right)=K\left(\max \left\{x_{e}, x_{u}\right\}\right)^{1-\gamma}
$$

where $x_{e}=\max \left\{w / r_{j}\right\}_{j=1}^{n}$ and $x_{u}=w_{0} / r_{0}$. Each ratio, $x_{j}=w_{j} / r_{j}$ has cumulative distribution $1-F\left(w_{j} / x_{j}\right)$. The random variable $x_{e}$ is an order statistic with cumulative distribution $[1-F(w / x)]^{n}$. Thus $x=\max \left\{x_{e}, x_{u}\right\}$ is a random variable that has cumulative distribution $G(x)=[1-F(w / x)]^{n}\left[1-F\left(w_{0} / x\right)\right]$. Differentiating yields density function:

$$
g(x)=\frac{n w\left[1-F\left(\frac{w}{x}\right)\right]^{n-1}\left[1-F\left(\frac{w_{0}}{x}\right)\right] f\left(\frac{w}{x}\right)+w_{0}\left[1-F\left(\frac{w}{x}\right)\right]^{n} f\left(\frac{w_{0}}{x}\right)}{x^{2}}
$$

Average utility is equal to a typical worker's expected utility and can therefore be written as

$$
E U=K \int x^{1-\gamma} g(x) d x
$$

As before, consider the case when $F$ is the Pareto distribution. If $w \geq w_{0}$ then we can write $g$ as

$$
g(x)=\left\{\begin{array}{ll}
\frac{a(n+1)}{x}\left(\frac{b x}{w}\right)^{a n}\left(\frac{b x}{w_{0}}\right)^{a} & \text { if } x \leq \frac{w_{0}}{b} \\
\frac{a n}{x}\left(\frac{b x}{w}\right)^{a n} & \text { if } \frac{w_{0}}{b} \leq x \leq \frac{w}{b}
\end{array} .\right.
$$

If $w \leq w_{0}$ then $g$ can be written as:

$$
g(x)=\left\{\begin{array}{ll}
\frac{a(n+1)}{x}\left(\frac{b x}{w}\right)^{a n}\left(\frac{b x}{w_{0}}\right)^{a} & \text { if } x \leq \frac{w}{b} \\
\frac{a}{x}\left(\frac{b x}{w_{0}}\right)^{a} & \text { if } \frac{w}{b} \leq x \leq \frac{w_{0}}{b}
\end{array} .\right.
$$


Thus

$$
E U=K\left\{\begin{array}{lc}
\frac{a(n+1)}{a(n+1)+1-\gamma}\left(\frac{w_{0}}{w}\right)^{a n}\left(\frac{w_{0}}{b}\right)^{1-\gamma}+\frac{a n}{a n+1-\gamma}\left[\left(\frac{w}{b}\right)^{1-\gamma}-\left(\frac{w_{0}}{w}\right)^{a n}\left(\frac{w_{0}}{b}\right)^{1-\gamma}\right] & \text { if } w \geq w_{0} \\
\frac{a(n+1)}{a(n+1)+1-\gamma}\left(\frac{w}{w_{0}}\right)^{a}\left(\frac{w}{b}\right)^{1-\gamma}+\frac{a}{a+1-\gamma}\left[\left(\frac{w_{0}}{b}\right)^{1-\gamma}-\left(\frac{w}{w_{0}}\right)^{a}\left(\frac{w}{b}\right)^{1-\gamma}\right] & \text { if } w \leq w_{0}
\end{array}\right.
$$

where $n=n^{*}$ and $w=w^{*}\left(n^{*}\right)$.

Given the complexity of this expression, analytic welfare calculations are not possible. However, numeric computations can be used to evaluate the welfare consequences of a minimum wage. Some of these results are presented in Table 1. What appears to be true is that for this model, assuming that the $r_{j}$ are distributed Pareto, minimum wages unambiguously increase welfare. Since as is common with monopsonistic competition, minimum wages have opposing welfare effects (increasing wages vs declining job choices and potentially declining employment), we do not believe that this unambiguous welfare result is robust to modelling changes or even changes in the assumed distribution of the $r_{j}$. Nevertheless, it is useful to observe that welfare can increase even as employment falls so that the literature's preoccupation with the employment effects of minimum wages may be misguided.

\section{Concluding Comments}

We have developed a simple model of monopsonistic competition, where each employer competes equally with all other employers for workers. This is similar to a Dixit-Stiglitz style model, although it is based on heterogeneous workers, each of whom only works for one employer. We find that the effect of a small, binding minimum wage is ambiguous: it will be positive if the labor market is relatively distorted, and negative otherwise.

One point worth emphasizing is that even for labor markets that to all appearances is competitive, a moderately chosen minimum wage can increase employment. For ex- 
ample labor market concentration might be considered a useful statistic for judging the competitiveness of the labor market. However, as we have demonstrated, even for quite large $n$, a minimum wage can still increase employment.

\section{References}

Bhaskar, V., A. Manning and T. To, “Oligopsony and Monopsonistic Competition in Labor Markets," Journal of Economic Perspectives, 16(2):155-174, 2002.

Bhaskar, V. and T. To, “Minimum Wages for Ronald McDonald Monopsonies: A Theory of Monopsonistic Competition," Economic Journal, 109:190-203, 1999.

Burdett, K. and D. T. Mortensen, “Wage Differentials, Employer Size, and Unemployment," International Economic Review, 39(2):257-273, 1998.

Card, D. and A. B. Krueger, Myth and Measurement: The New Economics of the Minimum Wage, Princeton, New Jersey: Princeton University Press, 1995.

Manning, A., Monopsony in Motion, London, UK: London School of Economics Press, 2002.

McCue, K. and W. R. Reed, “New Empirical Evidence on Worker Willingness to Pay for Job Attributes," Southern Economic Journal, 62(3):647-653, 1996.

Sattinger, M., "Value of an Additional Firm in Monopolistic Competition," Review of Economic Studies, 51:321-332, 1984.

Walsh, F., “Comment on: 'Minimum Wages for Ronald McDonald Monopsonies: A Theory of Monopsonistic Competition'," Economic Journal, 113(489):718-722, 2001. 